\title{
Research of the wind energy resource distribution in the Baltic region
}

\author{
Prof. Dr.habil.sc.ing. Peteris Shipkovs ${ }^{1 *}$, Dr.sc.ing. Valery Bezrukov ${ }^{2}$,Dr.habil.sc.ing. Vladislav Pugachev ${ }^{3}$, \\ PhD Vladislavs Bezrukovs ${ }^{4}$, Ing. Vladimirs Silutins ${ }^{5}$ \\ ${ }^{1}$ Institute of Physical Energetics (IPE), Riga, LV-1006, LATVIA \\ ${ }^{2}$ Institute of Physical Energetics, Riga, LV-1006, LATVIA \\ ${ }^{3}$ Institute of Physical Energetics, Riga, LV-1006, LATVIA \\ ${ }^{4}$ Ventspils College University, Ventspils (VeU), LV-3601, LATVIA \\ ${ }^{5}$ Encom Ltd, Riga, LV-1006, LATVIA \\ * Corresponding author: shipkovs@edi.lv
}

\begin{abstract}
Governmental support and the availability of large unpopulated areas on the coasts of the Baltic countries make attractive the use of these lands for siting large wind power plants (WPP).

Studies in the area of wind energy resource distribution are carried out by the IPE with collaboration with the $\mathrm{VeU}$. The observations of wind speed were made using the measuring complex NRG LOGGER 9200 Symphonie.

The results of long-term observations on the wind energy density fluctuations at heights of 10 to $60 \mathrm{~m}$ in the area on the Baltic Sea coast of Latvia are presented in the form of tables, bar charts and graphs.

The wind speed distribution is analysed. The coefficients of approximating functions for two areas of different terrain types have been calculated, and extrapolation results for the distribution curves of wind speed and energy density obtained.

The acoustic noise level distribution around a planned WPP has been modelled.
\end{abstract}

Keywords: wind energy, wind energy density fluctuations, measurement of wind speed, acoustic noise level.

\section{Introduction}

The availability of large unpopulated coastal areas and the developed infrastructure of electric power networks in the Baltic countriesmake attractive the use of these areas for siting large wind power plants (WPP).

In the coastal territories of western Estonia, in the Ida-Virumaa region at the site of the former shale quarries the construction of WPPs is planned whose power will be over $600 \mathrm{MW}$. Further it is also planned to start offshore WPP construction.

In Latvia, projects on the construction of $450 \mathrm{MW}$ coastal WPPs have been approved; there are also projects as to the construction of a $900 \mathrm{MW}$ wind park offshore.

In Lithuania, the total power of wind parks in 2010 has made up $200 \mathrm{MW}$, with $1000 \mathrm{MW}$ to be reached; after 2020 it is planned to start works in the offshore territories.

In Latvia, planned preparation of the infrastructure is going on: construction of thermal power plants and of the transmission line "Kurzeme Arc" (by 2017), which would allow for construction of a 900 $M W$ WPP in the sea near Liepaja (by 2020). The governmental support is confirmed by working out administrative and legislative regulations as well as by creating a favourable tariff policy that would encourage the construction of large WPPs. At the same time, for the territory of the Baltic countries there are no databases of long-term measurements of wind speeds at different heights that can be used to compose an atlas of wind energy resource distribution in this region.

The systematic long-term measurements of wind speeds in Latvia since 2007, taking into account the wind speed distribution on several levels, have been carried out in the two sites: on the south-west coast of the Baltic Sea in the Ventspils region and on the north of the country in the Ainaži region in $35 \mathrm{~km}$ from the shore [1]. The places where the metrological masts are situated are shown on the map of Fig. 1 by black stars. On the same map, by dark grey colour the regions are indicated which, 
according to the forecasts of meteorological observations and being territorially remote from populated areas, could be promising for siting WPPs.

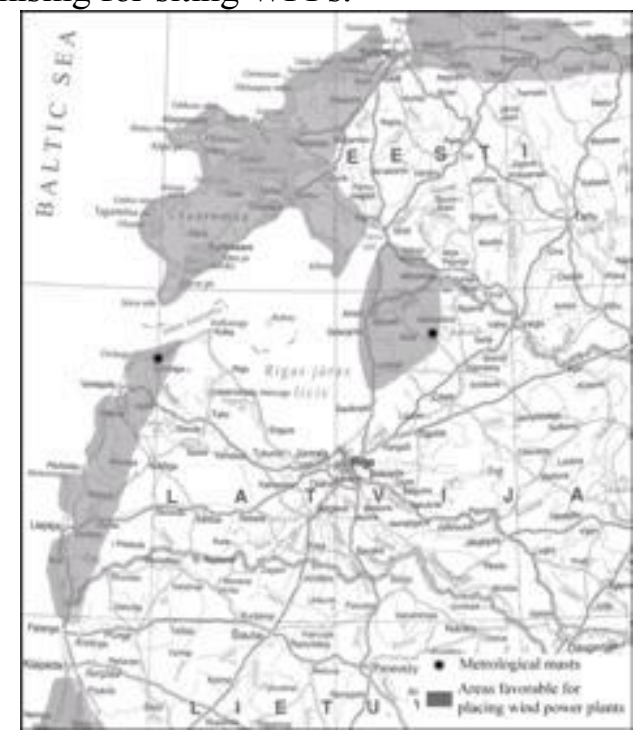

Figure 1 - The coastal map of Baltic countries with the places of interest for siting WPPs indicated.

\section{Research on the cyclic behaviour of wind energy fluctuations}

The measurements of wind speed were carried out using certified sensors of wind speed of the NRG \#40 type and sensors indicating the direction of the air stream of the NRG \#200P type. The sensors are arranged on metallic masts with the height of 53 and $60 \mathrm{~m}$ above the ground.

The periodicity of the information read-out from the sensors at all the height levels was $10 \mathrm{~s}$. For storing information an NRG LOGGER Symphonie complex was employed, which has independent supply from batteries and is able to store information from nine sensors in the memory card during a year.

In the observation period a database has been built up containing the wind speed values at heights of $10,20,30,40,50$ and $60 \mathrm{~m}$, wind temperature and direction in two regions in the Latvian territory. At the present time, the database contains more than 2500000 records of measurements. To compare the wind energy flow levels on the sea shore in the Ventspils region and in the area remote from the sea in the Ainaži region, in Table 1 average wind speed values, $V_{a}$, are given, with standard deviations $S D$, and the wind energy density values, $P_{d}, W / \mathrm{m}^{2}$. Dark colour in the table corresponds to a larger value of wind speed or energy density for the month.

The charts of seasonal fluctuations of average wind speed $V(\mathrm{~m} / \mathrm{s})$ for the measurement period $T$ ( $a$ month) at the heights 20,30, 40, $50 \mathrm{~m}$ in the Ventspils region and 10, 30, 50, $60 \mathrm{~m}$ in the Ainaži region are shown in Figs. 2 and 3.

The results of wind speed measurements taken in the Ventspils and Ainaži regions are systematized and presented in the form of histogram in Figs.4 and 5. The envelope of the histogram shows the wind speed $V$ distribution in the relative frequency of repetition $F$, which corresponds to the relation $F=\frac{T_{V}}{T}=100 \%$ where $T_{V}$ is the total duration of wind with the speed $V$ in the whole measurement period $T$ for the heights 20,30,40,50 $\mathrm{m}$ in the Ventspils region and 10,30,50,60 $\mathrm{m}$ in the Ainaži region.

The histogram allows determination of the wind energy flow density, which is calculated by the formula:

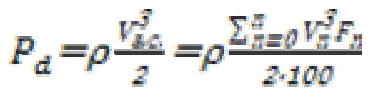

where $V_{\text {a.c. }}-$ is the average cubic wind speed, $\mathrm{m} / \mathrm{s}$,

$\rho=1.23 \mathrm{~kg} / \mathrm{m} 3-$ is the air density at atmosphere pressure $101.325 \mathrm{kPa}$ and temperature $15^{\circ} \mathrm{C}$,

$V_{n}-$ is the wind speed, $\mathrm{m} / \mathrm{s}$, 
$F_{n}$ - is the relative frequency of repetition, $\%$, corresponding to wind speed $V_{n}$ and determined by curves on the histograms of Figs. 4 and 5 .

From analysis of statistical data for 2009/2010 shown in Fig.6 it follows that in the coastal zone winds are gustier, whereas farther from shore their speeds are more uniform. The maximum value for separate wind gusts lasting not less than 10s in the Ventspils region is not much higher than in Ainaži, with the situation changing in individual months. In January of 2005 the wind gusts in the Ventspils region at a height of $50 \mathrm{~m}$ reached $34.1 \mathrm{~m} / \mathrm{s}$.

Table 1 - Distribution of average wind speed values with standard deviations and corresponding power density values at the height $50 \mathrm{~m}$ in the observation period

\begin{tabular}{|c|c|c|c|c|c|c|c|}
\hline \multirow{2}{*}{ Year } & \multirow[b]{2}{*}{ Month } & \multicolumn{3}{|c|}{ Ventspils } & \multicolumn{3}{|c|}{ Ainaži } \\
\hline & & $V_{a, m}, \mathbf{s}$ & $S D, m / s$ & $P_{d}, W / m^{2}$ & $V_{a}, m / s$ & $S D \mathrm{~m} / \mathrm{s}$ & $P_{d}, W / m^{2}$ \\
\hline \multirow{9}{*}{ ஓి } & April & 4.27 & 0.78 & 76.92 & 4.48 & 0.72 & 85.53 \\
\hline & May & 4.82 & 0.97 & 93.59 & 4.58 & 0.81 & 93.10 \\
\hline & June & 4.80 & 0.99 & 95.32 & 4.56 & 0.84 & 97.48 \\
\hline & July & 4.28 & 0.83 & 77.96 & 3.87 & 0.65 & 57.99 \\
\hline & August & 4.37 & 0.80 & 73.82 & 4.14 & 0.67 & 64.92 \\
\hline & September & 5.04 & 1.03 & 113.19 & 4.61 & 0.74 & 83.86 \\
\hline & October & 4.78 & 1.07 & 151.59 & 5.00 & 0.79 & 139.02 \\
\hline & November & 4.97 & 1.12 & 103.52 & 4.73 & 0.79 & 84.99 \\
\hline & December & 4.23 & 0.88 & 81.45 & 3.98 & 0.63 & 66.16 \\
\hline \multirow{4}{*}{ 을 } & January & 3.60 & 0.67 & 56.48 & 3.01 & 0.43 & 47.71 \\
\hline & February & 3.58 & 0.74 & 47.95 & 3.32 & 0.48 & 43.83 \\
\hline & March & 4.88 & 1.08 & 105.12 & 4.91 & 0.81 & 107.57 \\
\hline & Average & 4.47 & 0.91 & 89.74 & 4.27 & 0.70 & 81.02 \\
\hline
\end{tabular}

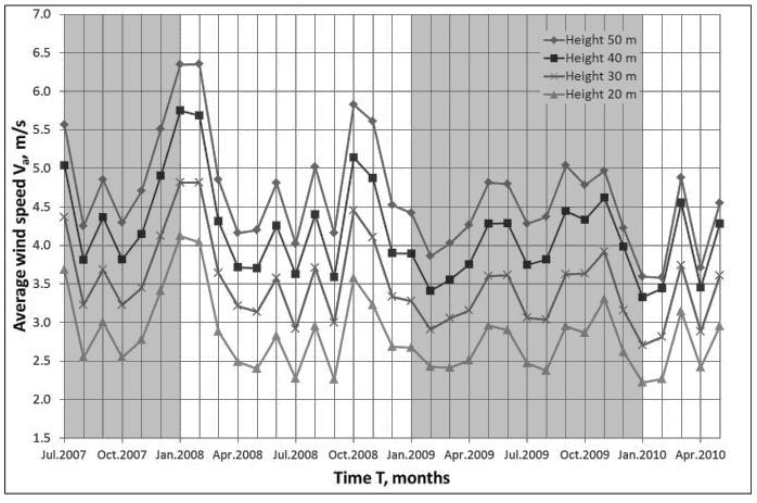

Figure 2 - Average wind speed values $V_{a}$ in period $T(2007 / 2010)$ at heights $10,30,40$ and 50 $m$ in the Ventspils region.

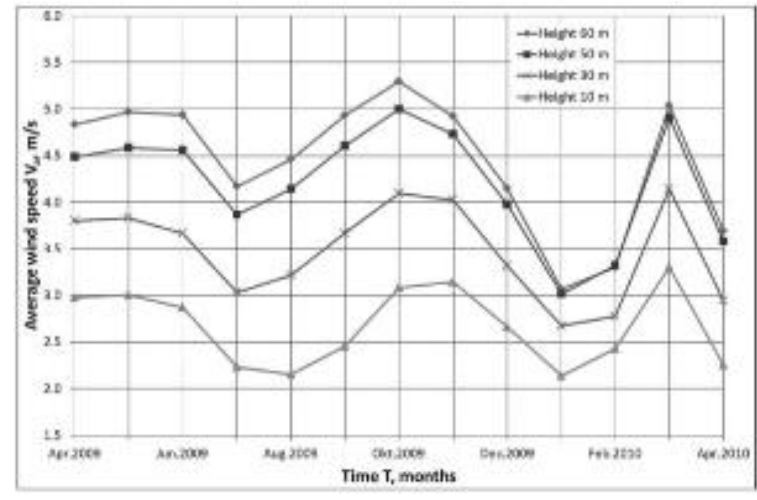

Figure 3 -Average wind speed values $V_{a}$ in period $T(2009 / 2010)$ at heights $10,30,50$ and 60 $m$ in the Ainaži region.

\section{Approximating functions for calculation of the wind speed and wind energy density up to $150 \mathrm{~m}$}

The distribution curves of the average wind speed $V_{a}(\mathrm{~m} / \mathrm{s})$ in height $h(\mathrm{~m})$ above the ground level in the regions Ventspils and Ainaži obtained based on the data accumulated for a long time are presented in Fig. 7. The measured values of wind speed in the Ventspils region are shown by two curves. Curve 1 corresponds to the average wind speed values in the period of 2007/2010, curve 2 - to the average wind speed values in the period of 2009/2010, and curve 3 - to the distribution of the average wind speed in the Ainaži region in the period of 2009/2010. 


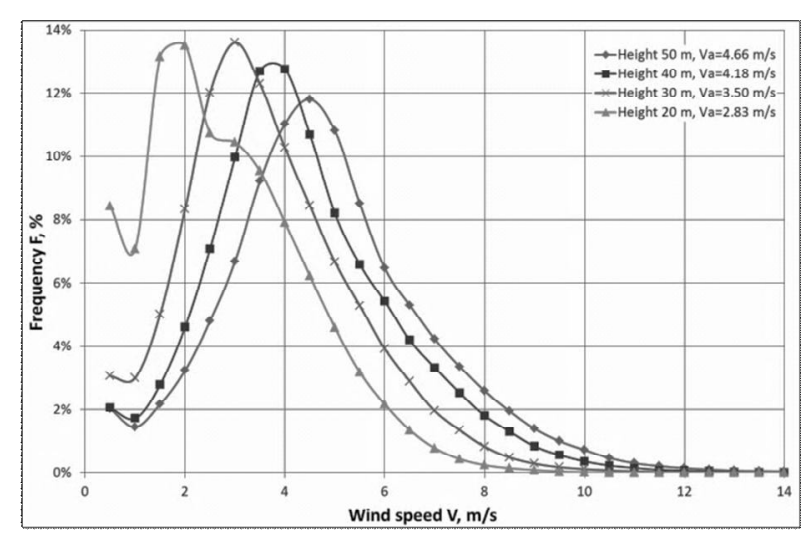

Figure 4 - Distribution of wind speed $V$ in relative frequency of repetition $F$ at heights $10,30,40$ and $50 \mathrm{~m}$ in the Ventspils region.

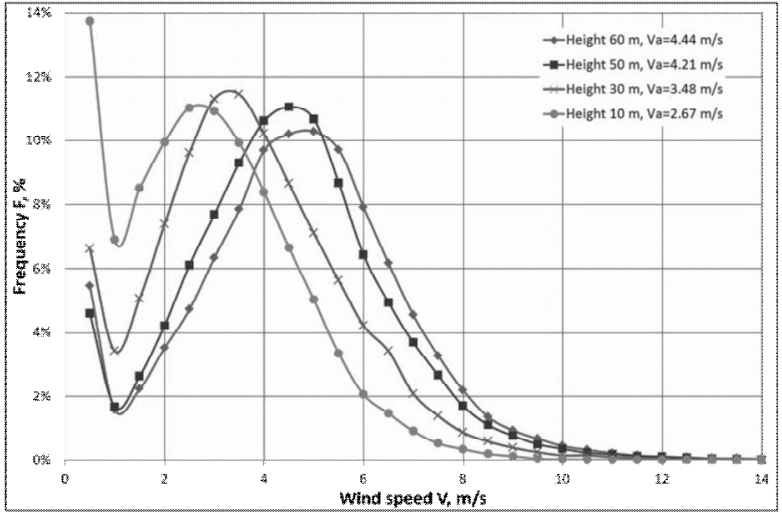

Figure 5 -Distribution of wind speed $V$ in relative frequency of repetition $F$ at heights 20,30,50 and $60 \mathrm{~m}$ in the Ainaži region

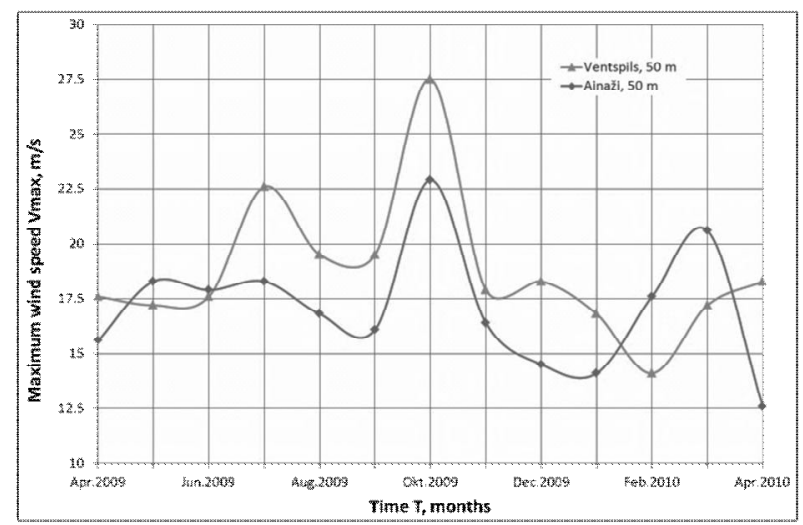

Figure 6 - The maximum values of separate wind gusts, $\mathrm{V}(\mathrm{m} / \mathrm{s})$, with duration $10 \mathrm{~s}$ in the regions Ventspils and Ainaži, at height $50 \mathrm{~m}$ above the ground level in the period of 2009/2010.

Analysis of the distribution curves in Fig.7 obtained for the average wind speed $V_{a}$ shows that the wind speed distribution in height up to $30 \mathrm{~m}$ is to a considerable extent determined by the topography of the terrain. In the Ventspils region it is represented by 8-10m high tract of forest, whereas in the Ainaži region - anopen plain remote from the sea. The points on the curves corresponding to the measured values of wind speed at a height over $30 \mathrm{~m}$ could be well approximated by the exponential function of the form:

$$
V_{a}=k h^{\alpha}
$$

For the curves of Fig. 7 the following values for approximating functions have been obtained:

For curve $1-V_{a}=1.22 h^{0.36}$, the coefficient of determination $R^{2}=0.9933$;

For curve $2-V_{a}=1.15 h^{0.36}$, the coefficient of determination $R^{2}=0.9899$;

For curve $3-V_{a}=1.03 h^{0.36}$, the coefficient of determination $R^{2}=0.9975$.

Fig.8 shows curves $1,2,3$ for measured values of the average wind speed $V_{a}(\mathrm{~m} / \mathrm{s})$, calculated using the corresponding values of approximating functions and extrapolated up to the height $h$ of $150 \mathrm{~m}$.

From analysis of the distribution of the average cubic wind speed depending on the height above the surface $V_{\text {a.c. }}=f(h)$ for curves $1,2,3$ the following coefficients and exponents have been obtained for approximating function (Eq. 2):

For curve $1-V_{a . c .}=1.72 h^{0.31}$, the coefficient of determination $R^{2}=0.987$;

For curve $2-V_{\text {a.c. }}=1.15 h^{0.31}$, the coefficient of determination $R^{2}=0.9861$;

For curve $3-V_{\text {a.c. }}=1.03 h^{0.29}$, the coefficient of determination $R^{2}=0.9989$.

With due regard for the relationship in expression (Eq. 1) the distribution curves for the average cubic wind speed values in height $V_{a . c .}=f(h)$ are calculated up to the height of $150 \mathrm{~m}$ and are presented in Fig.9. 
Correspondingly, the distribution curves for the wind energy density $P_{d}=f(h)$ are presented in Fig.10. For calculation of the wind energy density in the coastal area and in the regions remote from the coast by 30-40 $\mathrm{km}$ the following functions have been used:

For curve $1-P_{d}=3.31 h^{0.92}$, the coefficient of determination $R^{2}=0.9868$;

For curve $2-P_{d}=2.79 h^{0.92}$, the coefficient of determination $R^{2}=0.9863$;

For curve $3-P_{d}=2.62 h^{0.87}$, the coefficient of determination $R^{2}=0.999$.

For flat territories typical of the Baltic countries the approximating function (Eq. 2) could be reduced to the form more convenient for the use:

$$
\begin{gathered}
V_{a \cdot h}=V_{a \cdot h_{1}}\left(\frac{h}{h_{1}}\right)^{\alpha}(3) \\
V_{a \cdot h}=V_{a \cdot h_{1}}\left(\frac{h-h_{0}}{h_{1}-h_{0}}\right)^{\alpha}
\end{gathered}
$$

where $V_{a, h}$ is the calculated value of the average wind speed $(\mathrm{m} / \mathrm{s})$ at height $h,(\mathrm{~m})$;

$V_{a . h l}-$ is the measured value of the average wind speed $(\mathrm{m} / \mathrm{s})$ at height $h_{1},(\mathrm{~m})$ for a flat area;

$h_{0}-$ is the height of the surface relief at the installation point of the measuring set,

$\alpha-$ is the approximation coefficient (depending on the remoteness from the sea shore is $0,36-0,31$ ).

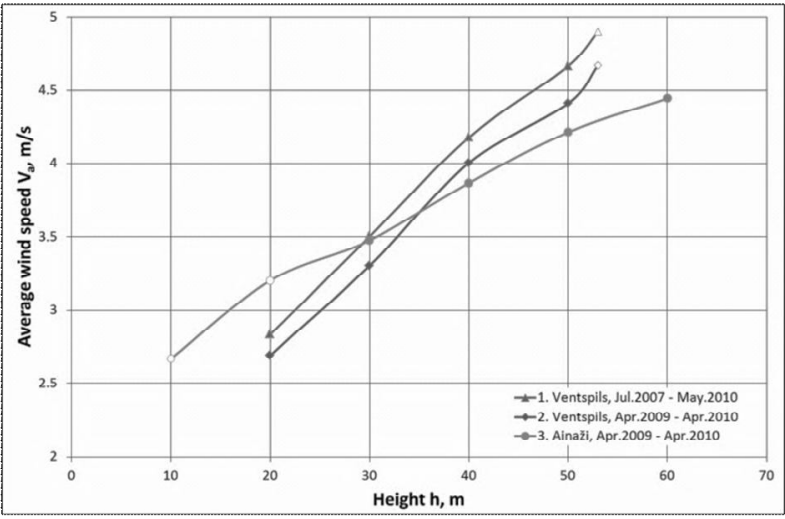

Figure 7 - The curves of the average wind speed $v s$. height $V_{a}=f(h)$ in the Ventspils and Ainaži regions obtained by measurements.

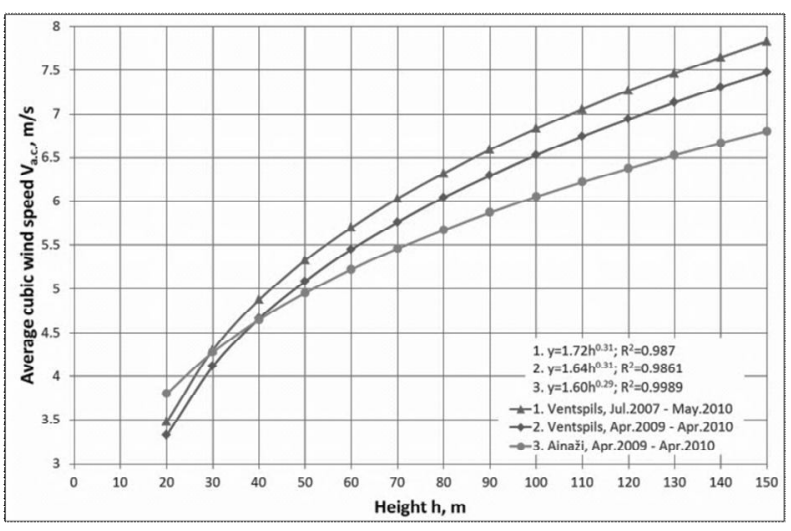

Figure 9 - The curves of the average cubic wind speed vs. height $V_{\text {a.c. }}=f(h)$ in the Ventspils and Ainaži regions extrapolated up to the height of $150 \mathrm{~m}$.

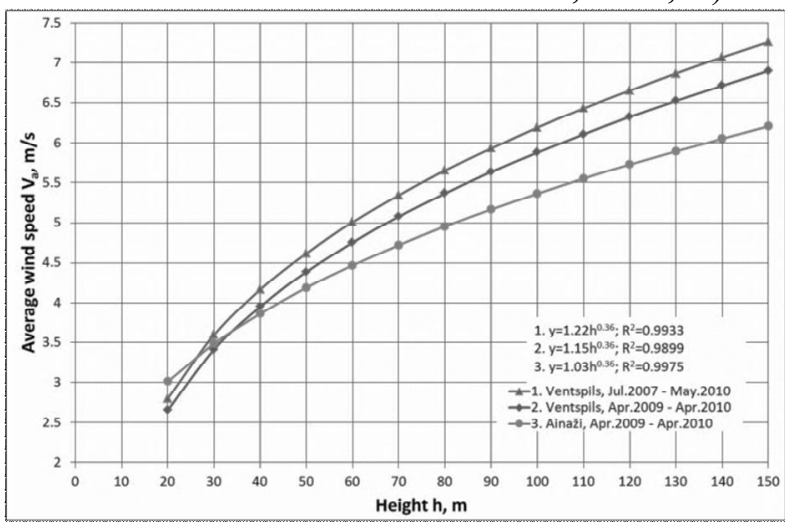

Figure 8 -The curves of the average wind speed $v s$. height $V_{a}=f(h)$ in the Ventspils and Ainaži regions extrapolated up to the height of $150 \mathrm{~m}$.

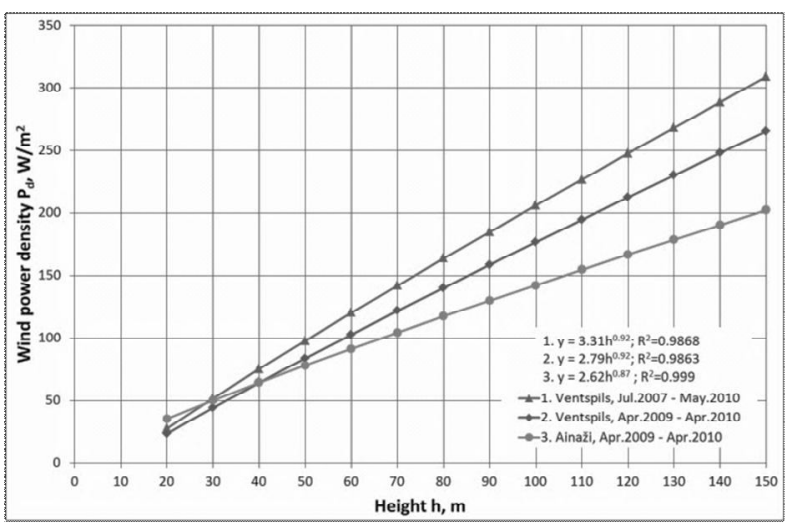

Figure 10- The curves of the wind energy density $v s$. height $P_{d}=f(h)$ in the Ventspils and Ainaži regions extrapolated up to the height of $150 \mathrm{~m}$

\section{Estimation of the acoustic noise level distribution around a WPP}

One of the negative aspects of WPP operation is emission of low-frequency noise that acts on humans and disturb comfortable life conditions. In compliance with the sanitary norms in Latvia the noise level accepted 
at the places of permanent residence of people must not exceed $40 \mathrm{~dB}(A)$. This means that the construction of WPPs in the proximity of settlements is not allowed.

Figure 11 shows the map of noise level distribution in the territory surrounding a WPP consisting of 14 generators with the total power of $35.0 \mathrm{MW}$. The maximum value of the noise level in the WPP territory is $53.0 d B(A)$, the noise level of a generator being $104.5 d B(A)[2]$.

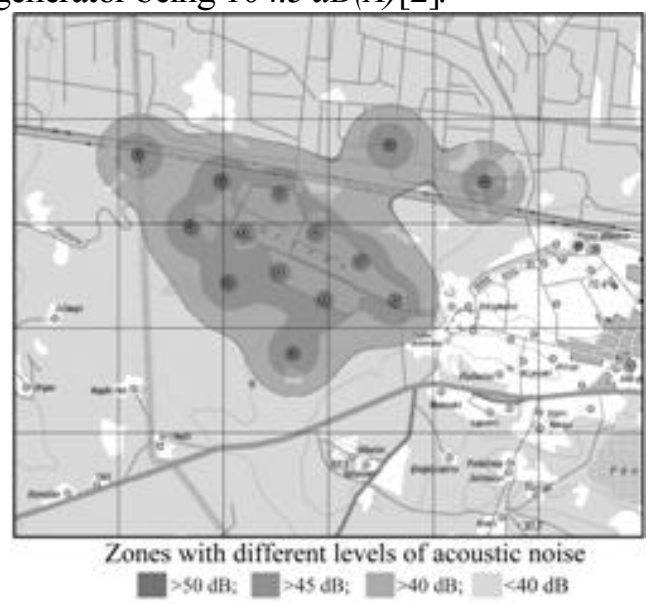

Figure 11 - The map of noise level distribution around a WPP consisting of 14 generators with the total power of $35.0 \mathrm{MW}$ in the territory $5000 \times 6000 \mathrm{~m}$.

\section{Conclusions}

1. Availability of large unpopulated areas on the coasts of the Baltic countries, along with the developed infrastructure of electric power networks, makes attractive the use of these lands for siting large wind power plants (WPPs).

2. During long-term observations a statistical database has been accumulated on the distribution of speeds and directions of winds at different heights: 10, 20, 30, 40, 50 and 60min the Ventspils and Ainaži regions on the Baltic Sea shore.

3. The graphs of seasonal fluctuations of wind speed have been obtained for the heights up to $60 \mathrm{~m}$ by measurements over the period of 2007-2010.

4. The histograms have been composed for the relative frequency of repetitionof wind speed over the period of 2007-2010.

5. The values of approximating functions have been obtained allowing for the calculations of the wind speed at a height up to $150 \mathrm{~m}$ above the ground level in coastal zones of the Baltic Sea and in a territory remote from the sea by $35 \mathrm{~km}$.

6. The wind speed measurements are noticeably affected by the terrain features, therefore to raise the precision at determination of approximating functions it is worthwhile to dispose the measuring sensors at a height over $30 \mathrm{~m}$ above the surface level.

7. During the period of observations it has been revealed that in 2009 the average yearly wind speed on the Baltic Sea shore decreased 5\% with respect to 2007. To compose the atlas of the wind energy resources it is necessary to investigate the period of cyclic yearly fluctuations of the wind speed.

8. The maximum values obtained for separate wind gusts lasting not less than $10 \mathrm{~s}$ are not much higher in the Ventspils region than in Ainaži. In January 2005 the wind gusts at a height of $50 \mathrm{~m}$ in the Ventspils region reached $34.1 \mathrm{~m} / \mathrm{s}$.

9. In the places of WPP location the level of acoustic noise can be higher than $53.0 \mathrm{~dB}(A)$, while in compliance with the sanitary norms the noise level allowable for residential areas must not exceed 40 $d B(A)$.

\section{References}

[1] V. Bezrukov, V. Pugachov, P. Shipkovs, G. Kashkarova, Vl. Bezrukovs „Investigation of the wind energy potential in the Baltic region". SCW2005, ISES Solar World Congress, August 6 - 12, Orlando, US, - 6 pp.

[2] P. Shipkovs, V. Bezrukov, Vl. Pugachov, Vl. Bezrukovs, S. Orlova „Measurements and utilization of wind energy on the Baltic Sea coast". The 10th World Renewable Energy Congress - WREC X, 19-25 July, 2008, Glasgow, Scotland, CD proceedings $2398-2403$. 